\title{
The Ross procedure and valve-sparing root replacement procedures in the adult patient: do guidelines follow the evidence?
}

\author{
Dominique Vervoort ${ }^{1}$, Ismail El-Hamamsy ${ }^{2}$, Michael W. A. Chu ${ }^{3}$, Mark D. Peterson ${ }^{4}$, Maral Ouzounian ${ }^{4}$ \\ ${ }^{1}$ Johns Hopkins Bloomberg School of Public Health, Baltimore, Maryland, USA; ${ }^{2}$ Department of Cardiovascular Surgery, Mount Sinai Hospital \\ and Icahn School of Medicine at Mount Sinai, New York, USA; ${ }^{3}$ Division of Cardiac Surgery, Western University, London, Canada; ${ }^{4}$ Division of \\ Cardiovascular Surgery, University of Toronto, Toronto, Ontario, Canada \\ Correspondence to: Maral Ouzounian, MD, PhD. Division of Cardiovascular Surgery, University of Toronto, Toronto, Ontario, Canada. \\ Email: maral.ouzounian@uhn.ca.
}

\begin{abstract}
Prosthetic aortic valve replacements have long been the mainstay of valvular surgery due to their favorable outcomes and low operative complexity. Yet, mechanical valves require lifelong anticoagulation, whereas bioprosthetic valves increase the risk for earlier and more frequent reoperation. Alternative reconstructive techniques have been proposed to address these challenges. These include valve-sparing root replacement procedures if the native aortic valve can be salvaged, and the Ross procedure, which nearly eliminates prosthetic valve-related thromboembolism, anticoagulation-related hemorrhage and endocarditis. Both procedures are technically more complex and thus subject to surgeons' volume and expertise compared to conventional aortic valve replacements. However, they are associated with more favorable outcomes compared to aortic valve replacements if performed by experienced surgeons, especially in younger patients. Nevertheless, despite the growing high-quality literature supporting both procedures, existing multisociety guidelines fail to acknowledge the strength of evidence in support of valve-sparing root replacement procedures and the Ross procedure. In this review, we summarize the existing long-term evidence for the use of each procedure, describe the current guidelines for the treatment of aortic valve pathology, and propose the reevaluation of guidelines based on the available clinical evidence.
\end{abstract}

Keywords: Aortic valve; valve surgery; valve-sparing; Ross procedure

Submitted Jan 01, 2021. Accepted for publication Apr 15, 2021.

doi: 10.21037/acs-2021-rp-24

View this article at: http://dx.doi.org/10.21037/acs-2021-rp-24

\section{Introduction}

The goal of correcting aortic valve pathology is to restore hemodynamics, ensure long-term valve durability and optimize long-term outcomes and survival. For decades, prosthetic heart valve replacements have been the mainstay of valvular cardiac surgery because of the favorable outcomes and the relatively low operative complexity. However, despite technological, technical and clinical advances in the field, contemporary valve prosthetics have substantial limitations as mechanical valves are associated with the need for lifelong anticoagulation and risk of thromboembolism, whereas bioprosthetic valves pose increased risk for earlier and more frequent reoperation.

To address the challenges with aortic valve replacements
(AVR), alternative reconstructive techniques have been introduced. In patients with good quality cusps and aortic root dilatation, valve-sparing root replacement (VSRR) procedures have become standard of care for preservation of the native valve through aortic valve reimplantation or aortic root remodeling. For patients whose aortic cusps are not salvageable, the Ross procedure provides an alternative to AVR that confers improved hemodynamics and nearly eliminates the prosthetic valve-related complications of thromboembolism, anticoagulation-related hemorrhage and endocarditis. This is especially important in young patients with aortic valve disease, given the higher lifetime risk of prosthesis-related complications associated with prosthetic AVR. However, early experiences with the Ross procedure 


\begin{tabular}{|c|c|c|}
\hline Guidelines & $\begin{array}{l}\text { Aortic valve-sparing } \\
\text { operation }\end{array}$ & Ross procedure \\
\hline 2014 ACC/AHA (5) & Class I & Class IIb \\
\hline 2016 CCS (6) & $\begin{array}{l}\text { Strong } \\
\text { recommendation }\end{array}$ & $\begin{array}{l}\text { Alternative to } \\
\text { AVR (strong) }\end{array}$ \\
\hline 2017 ESC/EACTS (7) & $\begin{array}{l}\text { To consider in } \\
\text { experienced centers }\end{array}$ & Not mentioned \\
\hline 2013 STS (8) & Class I & Class III \\
\hline \multicolumn{3}{|c|}{$\begin{array}{l}\text { ACC, American College of Cardiology; AHA, American Heart } \\
\text { Association; CCS, Canadian Cardiovascular Society; EACTS, } \\
\text { European Association for Cardio-Thoracic Surgery; ESC, } \\
\text { European Society of Cardiology; STS, Society of Thoracic } \\
\text { Surgeons. }\end{array}$} \\
\hline
\end{tabular}

were less favorable due to limited experience and may have contributed to poor uptake of the procedure. Early in the 21 st century, the proportion of patients requiring aortic valve surgery receiving a VSRR increased from $10 \%$ to $15 \%$, whereas the Ross procedure declined to less than $0.1 \%$ of aortic valve procedures in $2010(1,2)$.

The Ross procedure and VSRR are both niche operations that are technically more complex than conventional AVR. As a result, they are more techniquedependent and subject to surgeons' volume and expertise, and thus are typically offered by high-volume centers and surgeons. Between 2004 and 2010, the median number of aortic root replacements performed annually per center in North America was only two, whereas only five percent of centers performed more than sixteen root replacements per year (1). This is important in light of the established volume-outcome relationship and learning curve associated with complex aortic surgery such as VSRR $(3,4)$. The benefits of both procedures are substantial: the Ross procedure and VSRR both seek to reconstruct the aortic valve, and thus avoid valve-related adverse events associated with AVR. Nevertheless, both procedures are subject to concerns regarding generalizability and durability. Interestingly, VSRR has been more widely disseminated and accepted by the cardiac surgery community than the Ross procedure, achieving a much more favorable position in our multi-society guidelines (Table 1). The American College of Cardiology (ACC)/ American Heart Association (AHA) guidelines and Society of Thoracic Surgeons (STS) guidelines both recommend
VSRR as class I evidence, whereas the Ross procedure is considered only class IIb (ACC/AHA), and received a class III recommendation from the STS $(5,8)$. The European Society for Cardiology (ESC) and European Association for Cardio-Thoracic Surgery (EACTS) recommend VSRR to be considered in experienced centers but fail to specify recommendations for the Ross procedure (7). To date, the Canadian Cardiovascular Society has been the only major cardiovascular society recommending the Ross procedure as an alternative to AVR in young patients (6).

We suspect there are several reasons for the greater acceptance and more widespread adoption of VSRR by the cardiac surgery community compared to the Ross procedure. First, there are a larger number of centers and surgeons that offer VSRR compared to the Ross procedure, thus leading to increased exposure for trainees and wider dissemination of the technique. Second, the alternative to VSRR in a patient with root pathology is a modified Bentall procedure, whereas the alternative to the Ross procedure is a simple AVR, which is technically easier and faster to perform. Concern has been raised around the operative complexity and increased risk of early complications with the Ross procedure compared to AVR. Third, the Ross procedure suffered a troubling reputation because of less favorable outcomes in early studies by centers with limited expertise, quickly ceasing the use of the Ross procedure in their practice. Lastly, critics have raised the issue of creating a two-valve problem with the Ross procedure due to the risk of degeneration and late reintervention for both the homograft and autograft. The complexity of reinterventions after the Ross procedure has also been raised as a concern by critics.

In this paper, we present an overview of the current longterm evidence supporting VSRR and the Ross procedure to allow the reader to objectively compare the level of evidence supporting each procedure. We describe the current guidelines for the treatment of aortic valve pathology and propose the reevaluation thereof based on the available clinical evidence.

\section{VSRR procedures}

Long-term outcomes after VSRR have been described as excellent by experienced teams, with survival after VSRR of between $80 \%$ and $94 \%$ at ten years after operation (9-11). David et al. reported that, at fifteen years after operation, $95 \%$ of patients are free from reoperation, whereas $91 \%$ are free from moderate or severe aortic insufficiency (12). 
Table 2 Freedom from reoperation in the aortic valve and freedom from moderate or severe aortic insufficiency after aortic valve-sparing root replacement operations. Adapted from David et al. (12)

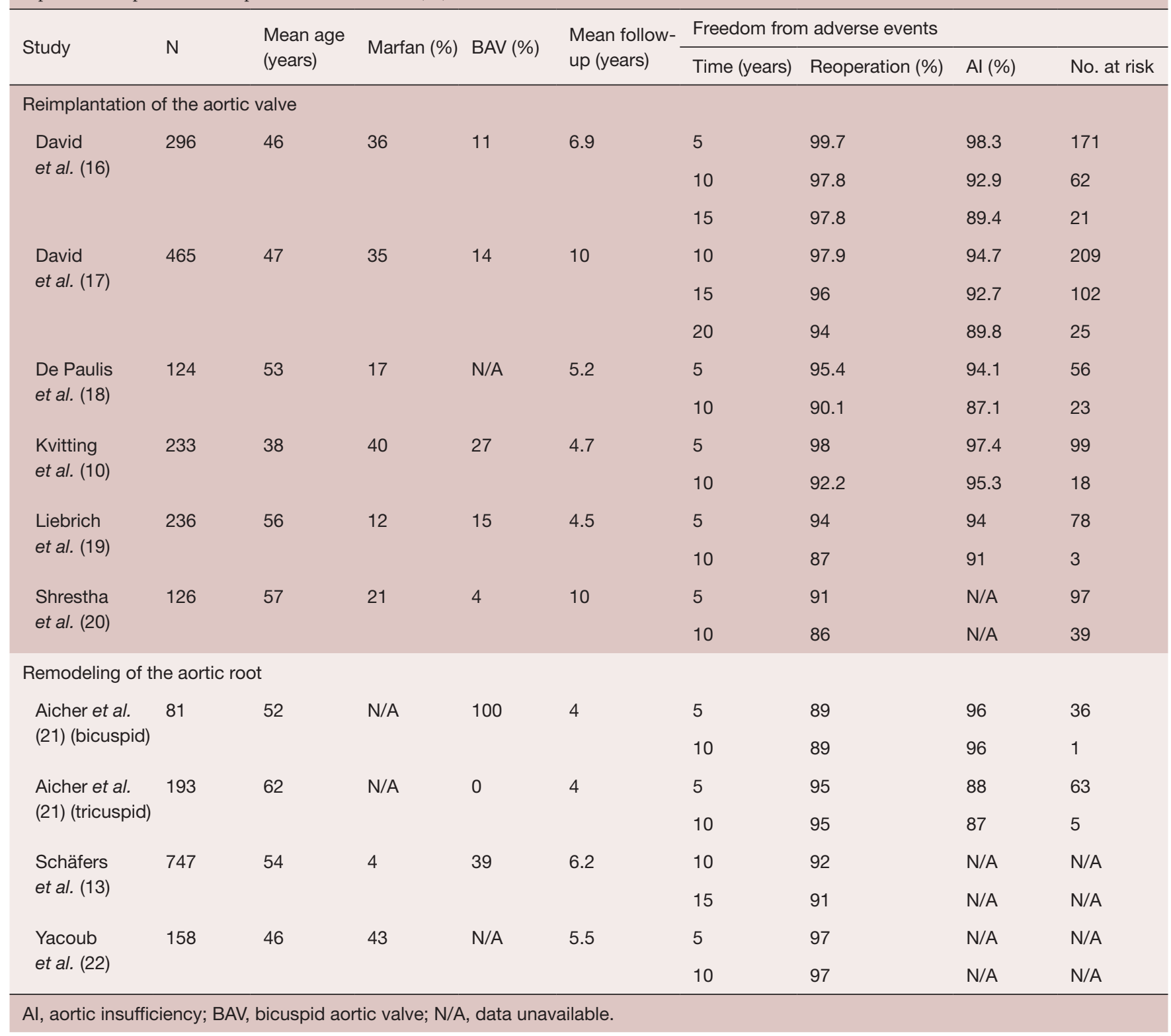

Schäfers et al. found that aortic root remodeling is a suitable technique for uni-, bi-, and tricuspid aortic valves with overall freedom of reoperation of $92 \%$ at ten years and $91 \%$ at fifteen years (13). Mastrobuoni et al. found a $90 \%$ and $88 \%$ freedom from aortic valve reoperation at ten years for bicuspid $(\mathrm{n}=164)$ and tricuspid aortic valves $(\mathrm{n}=253)$, respectively (9). Similar results were observed by Ouzounian et al., who found freedom from reintervention of $96 \%$ and $98 \%$ at ten years for bicuspid $(n=45)$ and tricuspid aortic valves ( $\mathrm{n}=134)$, respectively, suggesting comparable results for VSRR in carefully selected patients with either bicuspid or tricuspid aortic valves (14). Young patients with Marfan syndrome may derive particular benefit from a valvesparing approach, where results have been shown to be excellent (15). Table 2 summarizes the findings of major studies describing long-term outcomes after VSRR. The mean length of follow-up for these studies ranges from four to ten years. 


\section{The Ross procedure}

A large volume of literature has emerged showing excellent early and late outcomes of the Ross procedure. Similar to the VSRR literature, many centers with a large experience with the Ross procedure report excellent early and late results, with low operative mortality of less than $1 \%$. Performing a meta-analysis and microsimulation of approximately 10,000 patients across 27 studies, Sibilio et al. found a perioperative mortality of $2.5 \%$ for the Ross procedure in adult patients (23).

In Belgium, Mastrobuoni et al. reported a twenty-year experience performing the Ross procedure in 306 young patients with median follow-up of 10.6 years (24). Overall, survival at fifteen years was $88 \%$ with $97 \%$ freedom from valve-related mortality. In patients requiring reoperation, perioperative mortality was only $2.6 \%$, whereas the valve was preserved at reoperation in $70 \%$ of cases with no significant differences in postoperative survival. Moreover, freedom from any valve reoperation was as high as $75 \%$ at sixteen years. In Germany, utilizing the nationwide Ross Registry covering eight centers, Sievers et al. followed 1,779 patients for a mean of 8.3 years (25). Thirty-day mortality rate was $1.1 \%$ with late mortality comparable to the age- and gender-matched general population. Freedom from autograft and homograft reoperation was $86.7 \%$ and $92.3 \%$ at fifteen years, respectively. Similarly, Sievers et al. reported on 630 patients followed up over twenty-two years (median follow-up of 12.5 years), with twenty-year follow-up survival of $73.1 \%$ and freedom from reoperation of $85.9 \%$ (26). The risk of reoperation was found to be approximately $0.6 \%$ per patient-year, with autograft reoperation rates of $10 \%$ at twenty years, and approximately $80 \%$ of valves were considered in good to excellent clinical state after twenty years. Martin et al. followed 310 patients after the Ross procedure, of whom $98 \%$ were operated as elective procedures, for a median period of fifteen years between 1990 and 2014 (27). Freedom from any autograft or homograft (i.e., Ross-related) reoperation was $93 \%$ at ten years and $70 \%$ at twenty years, with a $5.6 \%$ mortality for reoperation but no significant difference in survival compared to the general population. David et al. reported a long-term (median eighteen years) follow-up of 212 patients with median age of thirty-four years, for whom autograft reoperation was necessary in $11.5 \%$ and any Ross-related reoperation in $14.1 \%$ at twenty years (28). Autograft regurgitation was observed in $13.0 \%$ and homograft dysfunction in $19.7 \%$ after twenty years, driven by older age, male sex, previous aortic regurgitation and time since operation. Pergola et al. followed 536 patients (mean age $29.4 \pm 11.1$ years) for a mean period of $16.3 \pm 4.9$ years with in-hospital mortality of $1.4 \%$ and twenty-year freedom from reintervention of $80 \%$ and $76 \%$ for the aortic and pulmonary valve, respectively (29). Caution has been raised regarding the risk of late failure in patients undergoing the Ross procedure for a bicuspid aortic valve with pure aortic insufficiency. Skillington and colleagues examined their results with this specific cohort and found excellent freedom from reoperation for AVR and more-than-mild aortic insufficiency at ten and twenty years post-surgery of $89 \%$ (95\% CI: $81-94 \%$ ) and $85 \%$ (95\% CI: $74-92 \%$ ), respectively (30). Table 3 summarizes contemporary studies describing the long-term outcomes after the Ross procedure in the adult patient. The mean length of follow-up for these papers is longer than for studies reporting late outcomes after VSRR and ranges from 8.2 to 16.3 years.

A critical factor limiting the more widespread adoption of the Ross procedure is the double-valve nature of the procedure, with particular concerns about the long-term function of the pulmonary homograft. Using the Canadian Ross Registry, Chauvette et al. reported on 466 patients with a mean age of forty-seven years at operation who were followed for a median of 2.2 years and up to 8.5 years (35). At six years, pulmonary homograft dysfunction was $11 \% \pm 2 \%$ and $0.9 \%$ required homograft reintervention. Younger age ( $<45$ years) at the time of the Ross procedure was found to be the only independent risk factor associated with pulmonary homograft dysfunction [hazard ratio (HR) 3.1]. Similarly, Fernández-Carbonell et al. followed 142 patients for twenty years after Ross, with homograft reintervention in $0.7 \%$ at one year and $9.1 \%$ at twenty years (36). Fricke et al. added to these results with their longitudinal study of 443 patients with mean age of thirtynine years at operation and mean follow-up of 9.3 years up to twenty-five years (37). Pulmonary allograft dysfunction was found in $11.9 \%$ at ten years and $21.7 \%$ at twenty years, with required pulmonary allograft reintervention in $2.3 \%$ and $3.4 \%$ at ten and twenty years, respectively.

Despite the favorable long-term results in large series, careful patient selection is required to minimize morbidity, mortality, and reoperations (Figure 1) $(29,38)$. The Ross procedure is most commonly proposed for nonelderly adults, and the age at which the incremental benefit of a Ross procedure is no longer relevant remains unclear. Chauvette et al. recently compared 232 patients older than 


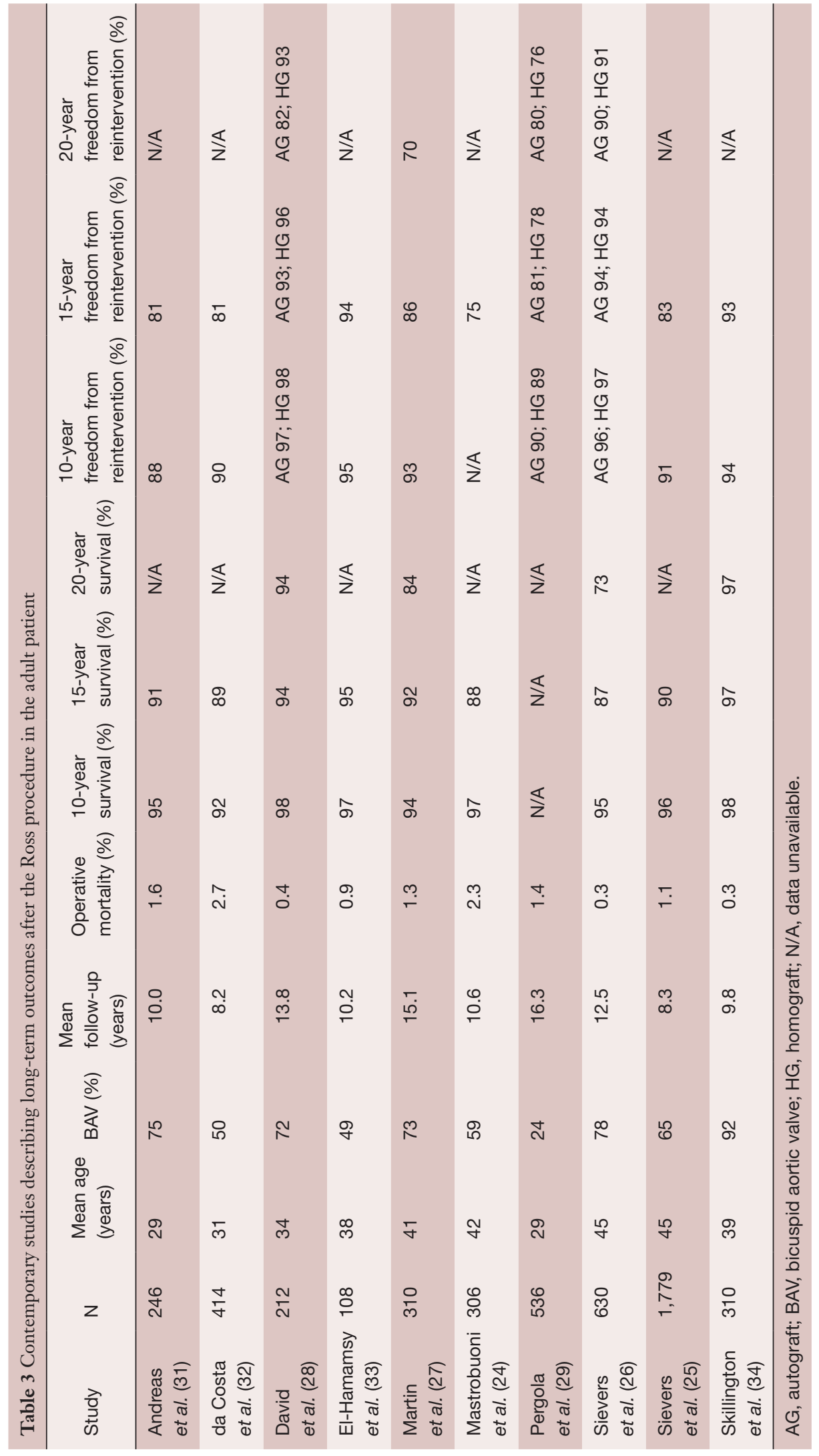

(C) Annals of Cardiothoracic Surgery. All rights reserved. ～Ann Cardiothorac Surg 2021;10(4):433-443 I http://dx.doi.org/10.21037/acs-2021-rp-24 


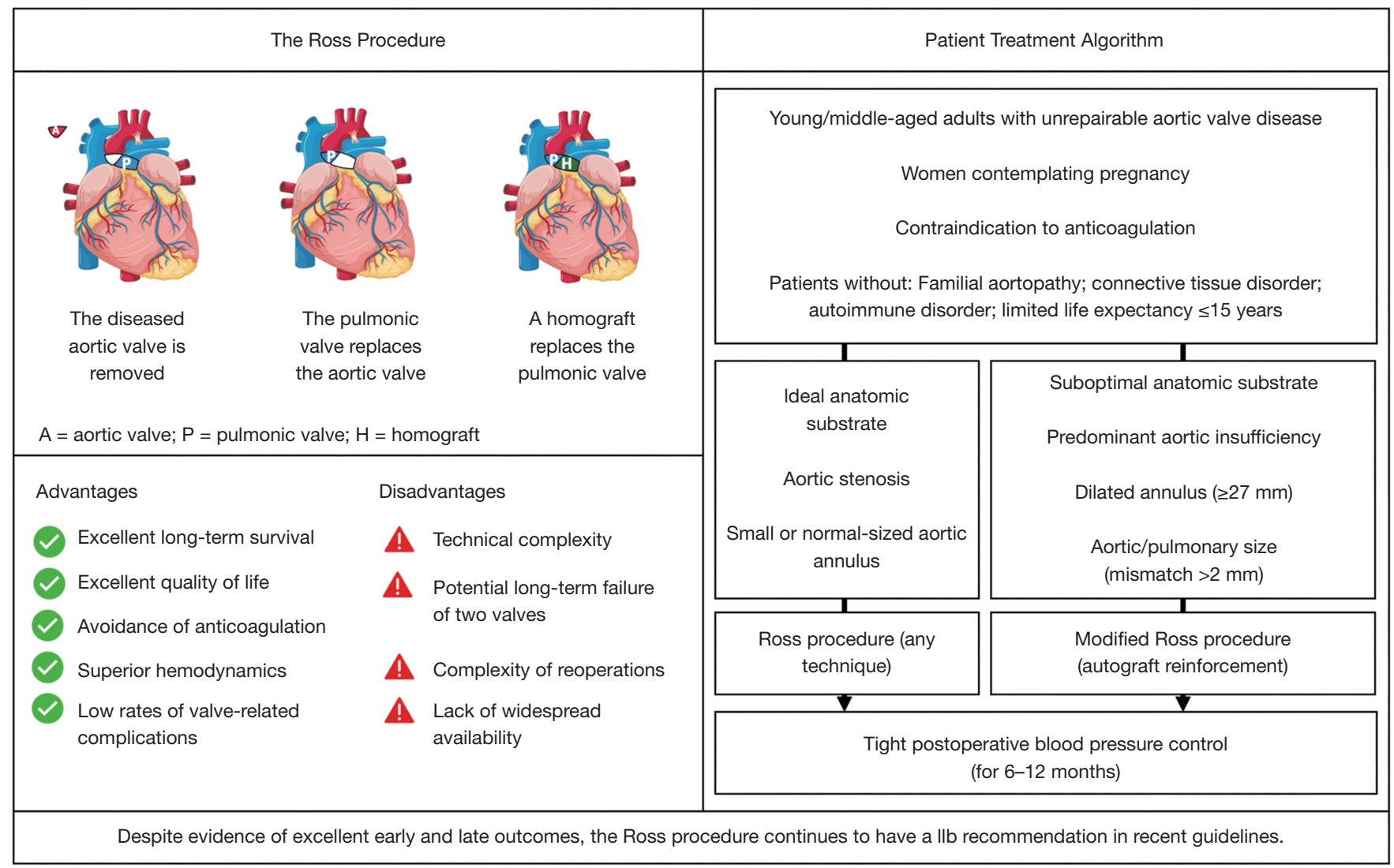

Figure 1 Algorithm for patient selection for the Ross procedure. Modified from Mazine et al. (38).

fifty years (mean $57 \pm 4$ years) with 265 patients younger than fifty (mean $38 \pm 10$ years) (39). In-hospital mortality was similar in both groups at $0.4 \%$, whereas cumulative six-year reintervention rates $(0.7 \% \pm 0.7 \%$ vs. $4 \% \pm 2 \%)$ and survival $(98 \% \pm 2 \%$ vs. $96 \% \pm 2 \%)$ did not significantly differ between patients older than fifty years compared to those aged fifty years or younger. Moreover, while the risk of reinterventions is low after primary Ross in specialized centers, reoperations can be performed with excellent outcomes and quality of life (40). Varrica et al. reoperated on sixty-four patients (forty-nine autograft, twenty-five homograft) with a median age of thirty-one years, followed up for a mean period of seventy-seven months (40). Patients reported high quality of life on follow-up, with only one non-cardiac-related death-encouraging results in the context of young patients facing a lifetime of consequences stemming from their valve-replacement choice.

\section{The learning curve for VSRR and the Ross procedure}

The Ross procedure and VSRR both prioritize valvular reconstruction and are associated with fewer valve-related adverse events compared to techniques that require prosthetic aortic valves. Their technical complexity, however, may be a barrier to broad adoption, and their long-term durability is dependent on patient selection and surgical technique. Current reports and long-term data supporting VSRR and the Ross procedure stem from experienced, high-volume centers and surgeons, reflecting the publication bias observed in complex procedures. As with many other complex operations, a volume-outcome relationship is evident and the learning curve necessary to adopt these procedures in a highly reliable manner is important. 
Stelzer et al. assessed the single-surgeon experience of 530 consecutive patients who underwent a Ross procedure between 1987 and 2013 in their center, with 3\% operative mortality in the first 100 cases, $2.4 \%$ in the second 125 cases and $0.0 \%$ in the last 305 cases despite a stable patient mix, finding a learning curve at approximately 100 cases (41). Similarly, Bouhout et al. illustrated that safety (morbidity and mortality) and efficiency endpoints (cross-clamp and bypass times) after the Ross procedure significantly improved after 75-100 cases from an all-comer population (42). Major complications significantly reduced from $11 \%$ to $4 \%$, whereas cross-clamp (194 \pm 29 vs. $170 \pm 28$ minutes) and bypass times ( $225 \pm 42$ vs. $205 \pm 37$ minutes) saw comparable improvements before and after the 100-case mark in a dedicated program. Similar but less pronounced learning curves have been observed for VSRR $(43,44)$. It is wellestablished that complex cardiac surgical procedures have important learning curves and that an adequate minimum annual volume (e.g., ten to fifteen operations) is preferred, yet a better understanding will be needed to inform surgeons seeking to adopt the Ross procedure and VSRR as part of their armamentarium. Nevertheless, these findings emphasize the need for technical expertise when considering the Ross procedure or VSRR.

\section{Considering the alternative}

The long-term survival and incidence of adverse events following either mechanical or bioprosthetic valve replacements is problematic. Goldstone et al. followed 9,942 patients undergoing AVR for a median of 5.0 (bioprosthetic, $\mathrm{n}=3,845$ ) to 8.2 years (mechanical, $\mathrm{n}=6,097$ ) between 1996 and 2013 (45). The use of bioprosthetic AVR increased from $11.5 \%$ to $51.6 \%$ during the study period, but fifteen-year mortality remained high for both bioprosthetic (30.6\% among $45-54$ year-old patients, $36.1 \%$ among $55-$ 64 year-old patients) and mechanical AVR (26.4\% among 45-54 year-old patients, $32.1 \%$ among 55-64 year-old patients). Bourguignon et al. used the Carpentier-Edwards Perimount bioprosthesis in 522 patients aged 50-65 years with $2 \%$ operative mortality and late mortality of $3 \%$ per valve-year (46). At twenty years follow-up, the actuarial survival rate was $35 \% \pm 5 \%$ and actuarial freedom from reoperation $50 \% \pm 6 \%$. In a Swedish cohort of 2,359 patients (1,776 mechanical and 583 bioprosthesis), isolated AVR was associated with substantial long-term morbidity and mortality, with fifteen-year survival of $70-74 \%$ in
$45-54$ year-old patients and $64-68 \%$ in $55-65$ year-old patients (47). Kvidal et al. reported higher than expected (i.e., excess) mortality after AVR, which was especially prevalent in younger patients (47). Composite valve graft procedures were found to be associated with significantly higher risks for major adverse valve-related events and cardiac mortality and comparable late durability compared with VSRR techniques (48). In a meta-analysis of twenty-six studies, Elbatarny et al. compared 3,794 patients undergoing composite valve grafting versus 2,424 undergoing VSRR with a mean follow-up of $5.8 \pm 3.0$ years (49). While no differences in early mortality and post-operative complications were observed, late mortality (incident rate ratio, 0.68 ; 95\% CI: $0.54-0.87)$, thromboembolism/ stroke (incident rate ratio, $0.36 ; 95 \%$ CI: $0.22-0.60$ ) and bleeding (incident rate ratio, $0.21 ; 95 \%$ CI: $0.11-0.42$ ) were significantly lower for VSRR compared to composite valve grafting.

Buratto et al. comparatively analyzed long-term survival after the Ross procedure $(\mathrm{n}=392)$ with isolated mechanical AVR $(\mathrm{n}=1,928)(50)$. Ten and twenty years after surgery, survival for Ross was 98\% (97-100\%) and 95\% (92-99\%), respectively, compared to only $88 \%(86-90 \%)$ and $68 \%$ (63-73\%) for mechanical AVR. Amine et al. performed a single-center propensity-matched cohort study of 208 pairs of Ross and mechanical AVR patients (mean age of $37.2 \pm 10.2$ years) with mean follow-up of $14.2 \pm 6.5$ years (51). Overall survival and freedom from reintervention were comparable but freedom from cardiac mortality and long-term freedom from stroke and major bleeding were improved in Ross compared to AVR. In a meta-analysis of 3,516 patients with median follow-up of 5.8 years, the Ross procedure was significantly associated with lower all-cause mortality (HR 0.54), lower stroke (HR 0.26), lower major bleeding (HR 0.17), and higher rates of reintervention (HR 1.76) compared to mechanical AVR in adults (52). Similarly, in a meta-analysis of 5,346 patients, McClure et al. found that the Ross procedure conferred a late survival benefit [late mortality relative risk (RR) 0.56 for Ross vs. AVR] with comparable reintervention rates compared to AVR (53). Applying a decision analysis microsimulation model, Tam et al. illustrated that the Ross procedure is expected to outperform mechanical AVR in terms of life expectancy when perioperative mortality for the Ross procedure is less than $2.5 \%$, which is the case in expert hands (54). Moreover, when comparing Ross versus AVR in young adults, the Ross procedure has been found to result in greater quality 
of life and more favorable cost-effectiveness compared to AVR $(55,56)$. Although large randomized clinical trials have not yet been completed, the use of a pulmonary autograft in young patients has clear benefits with respect to hemodynamics, valve-related complications, and improved survival compared with AVR.

\section{Balancing early and late outcomes-time to rewrite the guidelines?}

Similar to much of the data supporting surgical guidelines, contemporary data for VSRR and the Ross are largely retrospective, with the resulting limitations of observational studies. As expected, these reports study heterogeneous populations and are afflicted by selection bias and unknown confounders that are difficult to adjust. Moreover, sample sizes are generally relatively small with limited follow-up, although these have been longer for studies reporting on the Ross procedure and are certainly much longer than studies of transcatheter valve procedures. Additionally, existing disparities in thoracic aortic surgery may cloud current outcomes: recent results from the Canadian Thoracic Aortic Collaborative found that women were less likely to undergo aortic root reconstruction, including Ross and VSRR, with higher rates of mortality and morbidity compared to men (57). Lastly, VSRR and the Ross procedure are both done and reported on by experts, which likely skews the outcomes achieved as a result of the volume-outcome relationship and existing learning curve. Nevertheless, these limitations exist across the entire spectrum of cardiac surgery and do not detract from the importance of critically analyzing the literature when considering the options providing the best possible outcomes for our patients.

Current guidelines recommend that young adults requiring AVR should undergo mechanical AVR, despite the data supporting the Ross procedure for this patient population. The Ross procedure is the only valve replacement option that confers similar life expectancy as healthy individuals in the general population $(26,58,59)$. It is associated with very low valve-related complications, and reoperations only increase after the second decade; however, these are generally done with excellent outcomes and are preferred over earlier mortality. In carefully selected patients operated at experienced centers, the Ross procedure is the best choice for young patients with aortic valve disease that is non-repairable. Nevertheless, current guidelines do not reflect the published evidence and should be reconsidered.

\section{Conclusions}

In summary, VSRR and the Ross procedure are both technically more complex than their alternatives but confer better long-term outcomes for carefully selected patients. Both techniques are subject to patient selection, surgical expertise, and exhibit a volume-outcome relationship. Despite their discrepant positions in current guidelines, the Ross procedure is supported by at least as much, if not more data than the literature supporting VSRR. The next iteration of our multi-society guidelines should recognize the growing and promising role of the Ross procedure in the aortic surgeons' toolbox.

\section{Acknowledgments}

Funding: None.

\section{Footnote}

Conflicts of Interest: The authors have no conflicts of interest to declare.

Open Access Statement: This is an Open Access article distributed in accordance with the Creative Commons Attribution-NonCommercial-NoDerivs 4.0 International License (CC BY-NC-ND 4.0), which permits the noncommercial replication and distribution of the article with the strict proviso that no changes or edits are made and the original work is properly cited (including links to both the formal publication through the relevant DOI and the license). See: https://creativecommons.org/licenses/by-nc-nd/4.0/.

\section{References}

1. Stamou SC, Williams ML, Gunn TM, et al. Aortic root surgery in the United States: A report from the Society of Thoracic Surgeons database. J Thorac Cardiovasc Surg 2015;149:116-122.e4.

2. Reece TB, Welke KF, O'Brien S, et al. Rethinking the Ross Procedure in Adults. Ann Thorac Surg 2014;97:175-81.

3. Hughes GC, Zhao Y, Rankin JS, et al. Effects of institutional volumes on operative outcomes for aortic root replacement in North America. J Thorac Cardiovasc Surg 2013;145:166-70.

4. Mazine A, Stevens LM, Ghoneim A, et al. Developing skills for thoracic aortic surgery with hypothermic circulatory arrest. J Thorac Cardiovasc Surg 
2019;157:1360-1368.e8.

5. Nishimura RA, Otto CM, Bonow RO, et al. 2017 AHA/ ACC Focused Update of the 2014 AHA/ACC Guideline for the Management of Patients with Valvular Heart Disease: A Report of the American College of Cardiology/ American Heart Association Task Force on Clinical Practice Guidelines. J Am Coll Cardiol 2017;70:252-89.

6. Appoo JJ, Bozinovski J, Chu MWA, et al. Canadian Cardiovascular Society/Canadian Society of Cardiac Surgeons/Canadian Society for Vascular Surgery Joint Position Statement on Open and Endovascular Surgery for Thoracic Aortic Disease. Can J Cardiol 2016;32:703-13.

7. Falk V, Baumgartner H, Bax JJ, et al. 2017 ESC/EACTS Guidelines for the management of valvular heart disease. Eur J Cardiothorac Surg 2017;52:616-64. Erratum in: Eur J Cardiothorac Surg. 2017 Oct 1;52(4):832 . doi: 10.1093/ ejcts/ezx363.

8. Svensson LG, Adams DH, Bonow RO, et al. Aortic valve and ascending aorta guidelines for management and quality measures. Ann Thorac Surg 2013;95:S1-66.

9. Mastrobuoni S, de Kerchove L, Navarra E, et al. Longterm experience with valve-sparing reimplantation technique for the treatment of aortic aneurysm and aortic regurgitation. J Thorac Cardiovasc Surg 2019;158:14-23.

10. Kvitting JP, Kari FA, Fischbein MP, et al. David valvesparing aortic root replacement: equivalent mid-term outcome for different valve types with or without connective tissue disorder. J Thorac Cardiovasc Surg 2013;145:117-26, 127.e1-5; discussion 126-7.

11. David TE, Feindel CM, David CM, et al. A quarter of a century of experience with aortic valve-sparing operations. J Thorac Cardiovasc Surg 2014;148:872-9; discussion 879-80.

12. David TE. Aortic Valve Sparing in Different Aortic Valve and Aortic Root Conditions. J Am Coll Cardiol 2016;68:654-64.

13. Schäfers HJ, Raddatz A, Schmied W, et al. Reexamining remodeling. J Thorac Cardiovasc Surg 2015;149:S30-6.

14. Ouzounian M, Feindel CM, Manlhiot C, et al. Valvesparing root replacement in patients with bicuspid versus tricuspid aortic valves. J Thorac Cardiovasc Surg 2019;158:1-9

15. David TE, David CM, Manlhiot C, et al. Outcomes of Aortic Valve-Sparing Operations in Marfan Syndrome. J Am Coll Cardiol 2015;66:1445-53.

16. David TE, Armstrong S, Manlhiot C, et al. Long-term results of aortic root repair using the reimplantation technique. J Thorac Cardiovasc Surg 2013;145:S22-5.
17. David TE, David CM, Ouzounian M, et al. A progress report on reimplantation of the aortic valve. J Thorac Cardiovasc Surg 2021;161:890-899.e1.

18. De Paulis R, Chirichilli I, Scaffa R, et al. Long-term results of the valve reimplantation technique using a graft with sinuses. J Thorac Cardiovasc Surg 2016;151:112-9.

19. Liebrich M, Kruszynski MK, Roser D, et al. The David procedure in different valve pathologies: a single-center experience in 236 patients. Ann Thorac Surg 2013;95:71-6.

20. Shrestha M, Baraki H, Maeding I, et al. Long-term results after aortic valve-sparing operation (David I). Eur J Cardiothorac Surg 2012;41:56-61; discussion 61-2.

21. Aicher D, Langer F, Lausberg H, et al. Aortic root remodeling: ten-year experience with 274 patients. J Thorac Cardiovasc Surg 2007;134:909-15.

22. Yacoub MH, Gehle P, Chandrasekaran V, et al. Late results of a valve-preserving operation in patients with aneurysms of the ascending aorta and root. J Thorac Cardiovasc Surg 1998;115:1080-90.

23. Sibilio S, Koziarz A, Belley-Côté EP, et al. Outcomes after Ross procedure in adult patients: A meta-analysis and microsimulation. J Card Surg 2019;34:285-92.

24. Mastrobuoni S, de Kerchove L, Solari S, et al. The Ross procedure in young adults: over 20 years of experience in our Institution. Eur J Cardiothorac Surg 2016;49:507-12; discussion 512-3.

25. Sievers HH, Stierle U, Charitos EI, et al. A multicentre evaluation of the autograft procedure for young patients undergoing aortic valve replacement: update on the German Ross Registry†. Eur J Cardiothorac Surg 2016;49:212-8.

26. Sievers HH, Stierle U, Petersen M, et al. Valve performance classification in 630 subcoronary Ross patients over 22 years. J Thorac Cardiovasc Surg 2018;156:79-86.e2.

27. Martin E, Mohammadi S, Jacques F, et al. Clinical Outcomes Following the Ross Procedure in Adults: A 25-Year Longitudinal Study. J Am Coll Cardiol 2017;70:1890-9.

28. David TE, Ouzounian M, David CM, et al. Late results of the Ross procedure. J Thorac Cardiovasc Surg 2019;157:201-8.

29. Pergola V, Di Salvo G, Fadel B, et al. The long term results of the Ross procedure: The importance of candidate selection. Int J Cardiol 2020;320:35-41.

30. Poh CL, Buratto E, Larobina M, et al. The Ross procedure in adults presenting with bicuspid aortic valve and pure aortic regurgitation: $85 \%$ freedom from reoperation at 20 
years. Eur J Cardiothorac Surg 2018;54:420-6.

31. Andreas M, Seebacher G, Reida E, et al. A single-center experience with the ross procedure over 20 years. Ann Thorac Surg 2014;97:182-8.

32. da Costa FD, Takkenberg JJ, Fornazari D, et al. Longterm results of the Ross operation: an 18-year single institutional experience. Eur J Cardiothorac Surg 2014;46:415-22; discussion 422.

33. El-Hamamsy I, Eryigit Z, Stevens LM, et al. Longterm outcomes after autograft versus homograft aortic root replacement in adults with aortic valve disease: a randomised controlled trial. Lancet 2010;376:524-31.

34. Skillington PD, Mokhles MM, Takkenberg JJ, et al. Twenty-year analysis of autologous support of the pulmonary autograft in the Ross procedure. Ann Thorac Surg 2013;96:823-9.

35. Chauvette V, Bouhout I, Tarabzoni M, et al. Pulmonary homograft dysfunction after the Ross procedure using decellularized homografts-a multicenter study. J Thorac Cardiovasc Surg 2020. [Epub ahead of print]. doi:10.1016/ j.jtcvs.2020.06.139.

36. Fernández-Carbonell A, Rodríguez-Guerrero E, Merino-Cejas C, et al. Predictive Factors for Pulmonary Homograft Dysfunction After Ross Surgery: A 20-Year Follow-up. Ann Thorac Surg 2021;111:1338-44.

37. Fricke TA, Skillington PD, Shi WY, et al. Pulmonary Valve Function Late After Ross Procedure in 443 Adult Patients. Ann Thorac Surg 2020;109:1127-31.

38. Mazine A, El-Hamamsy I, Verma S, et al. Ross Procedure in Adults for Cardiologists and Cardiac Surgeons: JACC State-of-the-Art Review. J Am Coll Cardiol 2018;72:2761-77.

39. Chauvette V, Bouhout I, Tarabzoni M, et al. The Ross procedure in patients older than 50: A sensible proposition? J Thorac Cardiovasc Surg 2020. [Epub ahead of print]. doi:10.1016/j.jtcvs.2020.09.121.

40. Varrica A, Caldaroni F, Saitto G, et al. Outcomes and Quality of Life After Ross Reintervention: Would You Make the Same Choice Again? Ann Thorac Surg 2020;110:214-20.

41. Stelzer P, Itagaki S, Varghese R, et al. Operative mortality and morbidity after the Ross procedure: a 26- year learning curve. J Heart Valve Dis 2013;22:767-75.

42. Bouhout I, Ghoneim A, Poirier N, et al. Impact of the Learning Curve on Early Outcomes Following the Ross Procedure. Can J Cardiol 2017;33:493-500.

43. Beckmann E, Martens A, Krueger H, et al. Aortic valvesparing root replacement (David): learning curve and impact on outcome. Interact Cardiovasc Thorac Surg 2020;30:754-61.

44. Malas T, Saczkowski R, Sohmer B, et al. Is Aortic Valve Repair Reproducible? Analysis of the Learning Curve for Aortic Valve Repair. Can J Cardiol 2015;31:1497.e15-22.

45. Goldstone AB, Chiu P, Baiocchi M, et al. Mechanical or Biologic Prostheses for Aortic-Valve and Mitral-Valve Replacement. N Engl J Med 2017;377:1847-57.

46. Bourguignon T, Lhommet P, El Khoury R, et al. Very long-term outcomes of the Carpentier-Edwards Perimount aortic valve in patients aged 50-65 years. Eur J Cardiothorac Surg 2016;49:1462-8.

47. Kvidal P, Bergström PR, Hörte LG, et al. Observed and relative survival after aortic valve replacement. J Am Coll Cardiol 2000;35:747-56.

48. Ouzounian M, Rao V, Manlhiot C, et al. Valve-Sparing Root Replacement Compared with Composite Valve Graft Procedures in Patients With Aortic Root Dilation. J Am Coll Cardiol 2016;68:1838-47.

49. Elbatarny M, Tam DY, Edelman JJ, et al. Valve-Sparing Root Replacement Versus Composite Valve Grafting in Aortic Root Dilation: A Meta-Analysis. Ann Thorac Surg 2020;110:296-306.

50. Buratto E, Shi WY, Wynne R, et al. Improved Survival After the Ross Procedure Compared with Mechanical Aortic Valve Replacement. J Am Coll Cardiol 2018;71:1337-44.

51. Mazine A, David TE, Rao V, et al. Long-Term Outcomes of the Ross Procedure Versus Mechanical Aortic Valve Replacement: Propensity-Matched Cohort Study. Circulation 2016;134:576-85.

52. Mazine A, Rocha R V, El-Hamamsy I, et al. Ross Procedure vs Mechanical Aortic Valve Replacement in Adults: A Systematic Review and Meta-analysis. JAMA Cardiol 2018;3:978-87.

53. McClure GR, Belley-Cote EP, Um K, et al. The Ross procedure versus prosthetic and homograft aortic valve replacement: a systematic review and meta-analysis. Eur J Cardiothorac Surg 2019;55:247-55.

54. Tam DY, Wijeysundera HC, Ouzounian M, et al. The Ross procedure versus mechanical aortic valve replacement in young patients: a decision analysis. Eur J Cardiothorac Surg 2019;55:1180-6.

55. Thom H, Visan AC, Keeney E, et al. Clinical and costeffectiveness of the Ross procedure versus conventional aortic valve replacement in young adults. Open Heart 2019;6:e001047.

56. Zacek P, Holubec T, Vobornik M, et al. Quality of life after 
aortic valve repair is similar to Ross patients and superior to mechanical valve replacement: a cross-sectional study. BMC Cardiovasc Disord 2016;16:63.

57. Chung J, Stevens LM, Ouzounian M, et al. Sex-Related Differences in Patients Undergoing Thoracic Aortic Surgery. Circulation 2019;139:1177-84.

58. Skillington PD, Mokhles MM, Takkenberg JJ, et al. The

Cite this article as: Vervoort D, El-Hamamsy I, Chu MWA, Peterson MD, Ouzounian M. The Ross procedure and valvesparing root replacement procedures in the adult patient: do guidelines follow the evidence? Ann Cardiothorac Surg 2021;10(4):433-443. doi: 10.21037/acs-2021-rp-24
Ross procedure using autologous support of the pulmonary autograft: techniques and late results. J Thorac Cardiovasc Surg 2015;149:S46-52.

59. Misfeld M, Borger MA. The Ross procedure: Time to reevaluate the guidelines. J Thorac Cardiovasc Surg 2019;157:211-2. 